\title{
Awareness Regarding Cervical Cancer And Pap Smear Test As A Screening Tool Among Married And Unmarried Females Of Karachi
}

\author{
Warda Zanib, Shareaa Naz, Summaiya Munim, Hafsa Farhat, Alishba Solangi, Nadia Khalid
}

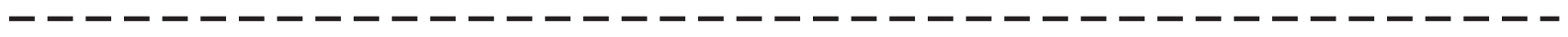

ABSTRACT

Objective: To determine the knowledge of risk factors of cervical cancer and Pap smear as screening tool in the prevention of disease among married and unmarried females of Karachi

Study Design and Setting: It was a crossectional study conducted from April until September 2018, a total duration of six months. Data has been collected from three different areas of Karachi.

Methodology: Non-probability convenient sampling techniques have been used to collect the data. Data collection was carried out by an interviewer based structured questionnaire. Data was entered and analysed using SPSS V 24. Pearson's chi square used as statistical test.

Results: 400 respondents with a mean age of $32.1+/-1.1$ years participated in the survey. $48.8 \%$ have heard about cervical cancer reflecting suboptimal knowledge. Major source of information amongst the females were health care providers. $21.8 \%(\mathrm{n}=87)$ of females considered HPV infection as a major risk factor followed by multiple sexual partners $(17.3 \%$, $\mathrm{n}=69)$ and early marriages $(16.5 \%, \mathrm{n}=66)$. Study showed $29.8 \%(\mathrm{n}=119)$ of respondents have heard about Pap smear while only $5 \%(n=20)$ of them had gone through this screening test.

Conclusion: The study revealed that knowledge regarding cervical cancer and Pap smear test is low among married and unmarried females. Attitudes and practices were not promising as the cost of test procedure seen as the main constraint.

Key Words: Cervical Cancer, Pap smear, Prevention, Screening.

\section{INTRODUCTION:}

Cervical cancer is one of the leading cause of morbidity and mortality amongst gynaecological cancers in the developing countries; however, it is a preventable disease. ${ }^{1}$ In the developed countries, pap smear screening is an easy clinical method for detection of cervical cancer and it is an essential part of woman's routine health care which is useful in detecting precancerous lesions as well as early cancers,

Warda Zanib

I Final Year Student

I Bahria University Medical and Dental College, Karachi

I Shareaa Naz

Final Year Student

I Bahria University Medical and Dental College, Karachi

Summaiya Munim

Final Year Student

I Bahria University Medical and Dental College, Karachi

I Hafsa Farhat

I Final Year Student

I Bahria University Medical and Dental College, Karachi

I Alishba Solangi

Final Year Student

Bahria University Medical and Dental College, Karachi

Nadia Khalid

I Research Supervisor - Student Project

I Senior Lecturer, Community Health Sciences

I Bahria University Medical and Dental College, Karachi

Received: 31-05-2019

Accepted: 20-06-2019 being the major factor responsible for significant decline in mortality rates due to cervical cancer. ${ }^{2}$ The main purpose is to detect abnormal cells that may develop into cancer if left untreated. According to medical recommendation, the first smear should be done at the age of 21 year or within 3 year of onset of sexual activity and thereafter every three years. ${ }^{2}$

Knowledge, attitude and practices of the community about cervical cancer and risk factors offer crucial opportunity for all embracing preventions and control techniques of the disease. ${ }^{3}$ Women's knowledge about cervical cancer and its preventive measures are limited in many developing countries mainly due to lack of education and awareness programs. ${ }^{4}$ Health care professionals are key persons to provide knowledge and facilities towards goals of cervical cancer prevention. ${ }^{5}$ Detection of cervical cancer at the early stages is linked with excellent survival but mostly the females present with advanced and often untreated disease with quite poor prognosis, ${ }^{6}$ this counts the significance of the detection of precancerous lesions with the aid of screening tool as pap smear.

Approximately, 500,000 women are diagnosed with invasive cancers of cervix per year across the world, killing 2,73,000 women however, number of cases are higher in developing countries where screening for cervical cancer is not widely practiced. ${ }^{7}$ According to $\mathrm{WHO}$, prevalence of cervical cancer in Pakistani women was $0.019 \%{ }^{8}$ Despite of low incidence of cervical cancer in Pakistan its mortality is higher. ${ }^{9}$ The 
Awareness Regarding Cervical Cancer And Pap Smear Test As A Screening Tool Among Married And Unmarried Females Of Karachi

reason of increased number of cervical cancer cases in Pakistan is the unawareness among women and lack of accessibility and availability of the screening test in rural areas of Pakistan. That results in progression of very advanced stage of malignancy and cause high rate of mortality in the country. ${ }^{10}$ This study aims to assess the knowledge and awareness regarding cervical cancers and its preventive measures, to determine the routine practices of Pap smear amongst females of Karachi and to compare the knowledge regarding cervical cancer amongst married and unmarried females.

\section{METHODOLOGY:}

It was a crossectional study conducted from April until September 2018, a total duration of six months. Data has been collected from three different areas of Karachi. Nonprobability convenient sampling technique has been used to collect the data. The sample size was calculated from openepi.com, the population size was kept 1 million, design effect being 1 with confidence limit $=5$ and anticipated frequency $=50 \%$. With confidence level $95 \%$, the sample size calculated was equal to 384 . Both married and unmarried females of age group 19-49 years were included in this study irrespective of any specific educational status. Females who have been exposed to cervical cancer or gone through Pap smear test were excluded from the study. Data collection was carried out by an interviewer based structured questionnaire. Data was entered and analysed using spss $\mathrm{V}$ 24. Pearson's chi square used as statistical test. Ethical permission taken from ethical review committee of Bahria University Medical and Dental College.

\section{RESULTS:}

According to demographic analysis, 400 respondents with a mean age of $32.1+/-1.1$ years participated in the survey, the majority of them being in the range of 18-33 years $(n=287,71.8 \%)$. The participants hailed from the different socio-economic backgrounds of Karachi, mostly being married females $(n=209,52.3 \%)$ and were having 4 children $(\mathrm{n}=136,75.5 \%)$. Amongst the married females mostly were married since last 2 years $(n=14,3.5 \%) .13 .8 \%$ of the respondents were working women $(\mathrm{n}=55)$. Significant history of abortions $(\mathrm{n}=56,14 \%)$ was also present in the participants.

119 participants had heard about Pap smear test and only 20 had gone through it. 215 females were willing to participate in the Pap smear screening test, if provided free of cost. Out of 161 females unaware of Pap smear, 78 respondents were willing for the screening and 42 stated denial even after provision of complete knowledge regarding it. Reluctance to do the Pap smear screening was abundantly observed in women who were never informed by their physician ( $p$ value $=0.00$ ) and due to family and religious restrictions ( $p$ value $=0.00$ ).

\section{DISCUSSION:}

Cervical cancer is one of the most common cancers among females. It is a slow growing cancer and its progression through precancerous changes provides opportunities for prevention, early diagnosis and treatment.

In our study, only $48.8 \%$ have heard about cervical cancer reflecting suboptimal knowledge. The level of knowledge

Table1: Knowledge Of Cervical Cancer And Papsmear

\begin{tabular}{|c|c|c|c|}
\hline VARIABLES & FREQUENCIES & $(\%)$ & \\
\hline & Yes & No & Don't know \\
\hline Have you ever heard about cervical cancer? & $195(48.8 \%)$ & $204(51.0 \%)$ & $1(3 \%)$ \\
\hline \multicolumn{4}{|l|}{ If yes, then from where did you get this information? } \\
\hline Family/Friends & $54(13.5 \%)$ & & \\
\hline TV & $35(8.8 \%)$ & & \\
\hline Doctors & $96(24.0 \%)$ & & \\
\hline Never Heard & $172(43.0 \%)$ & & \\
\hline Do you have family history of Cervical Cancer? & $23(5.8 \%)$ & $292(73.0 \%)$ & $85(21.3 \%)$ \\
\hline Is there a vaccine against cervical cancer? & $57(14.2 \%)$ & $82(20.5 \%)$ & $261(65.3 \%)$ \\
\hline \multicolumn{4}{|c|}{ What do you think are the signs and symptoms of Cervical Cancer? } \\
\hline Abnormal vaginal discharge & $77(19.3 \%)$ & $322(80.5 \%)$ & \\
\hline Persistent pain & $76(19.0 \%)$ & $324(81.0 \%)$ & \\
\hline Abnormal vaginal bleeding & $109(27.3 \%)$ & $291(72.8 \%)$ & \\
\hline Post-menopausal bleeding & $39(9.8 \%)$ & $361(90.3 \%)$ & \\
\hline Have you ever heard about pap smear? & $119(29.8 \%)$ & $161(40.3 \%)$ & $120(30.0 \%)$ \\
\hline
\end{tabular}


Warda Zanib, Shareaa Naz, Summaiya Munim, Hafsa Farhat, Alishba Solangi, Nadia Khalid

Table2: Knowledge Regarding Cervical Cancer Among Married And Unmarried Females

\begin{tabular}{|c|c|c|c|c|}
\hline & & Married & Unmarried & P-value \\
\hline \multirow[t]{2}{*}{ Have you ever heard about cervical cancer? } & Yes & $67(32.1 \%)$ & $128(67 \%)$ & \multirow{2}{*}{0.00} \\
\hline & No & $142(68.0 \%)$ & $63(33 \%)$ & \\
\hline \multirow[t]{3}{*}{ Is there a vaccine against cervical cancer? } & Yes & $15(7.2 \%)$ & $42(22 \%)$ & \multirow{3}{*}{0.00} \\
\hline & No & $32(15.3 \%)$ & $50(28.2 \%)$ & \\
\hline & Don't Know & $162(77.5 \%)$ & $99(51.8 \%)$ & \\
\hline \multirow[t]{5}{*}{ By which methods can cervical cancer be prevented? } & Vaccination & $51(24.4 \%)$ & $29(15.2 \%)$ & 0.02 \\
\hline & Avoiding multiple sexual partners & $15(7.2 \%)$ & $37(19.4 \%)$ & 0.00 \\
\hline & Not having sexual intercourse & $7(3.3 \%)$ & $16(8.4 \%)$ & 0.03 \\
\hline & All of the above & $11(5.3 \%)$ & $28(4.7 \%)$ & 0.04 \\
\hline & Don't know & $127(60.8 \%)$ & $82(42.9 \%)$ & 0.00 \\
\hline \multirow[t]{2}{*}{ Can cervical cancer cause infertility if left untreated? } & Yes & $123(58.9 \%)$ & $106(55.5 \%)$ & \multirow{2}{*}{0.00} \\
\hline & No & $3(1.4 \%)$ & $17(8.9 \%)$ & \\
\hline \multirow[t]{3}{*}{ What are signs and symptoms of cervical cancer? } & Abnormal vaginal discharge & $26(12.4 \%)$ & $51(26.7 \%)$ & 0.00 \\
\hline & Pain during sexual activity & $10(4.8 \%)$ & $36(18.8 \%)$ & 0.00 \\
\hline & Post-menopausal bleeding & $9(4.3 \%)$ & $30(15.7 \%)$ & 0.00 \\
\hline
\end{tabular}

Figure: 1 Attitude And Practices Of Pap Smear Amongst The Females Of Karachi

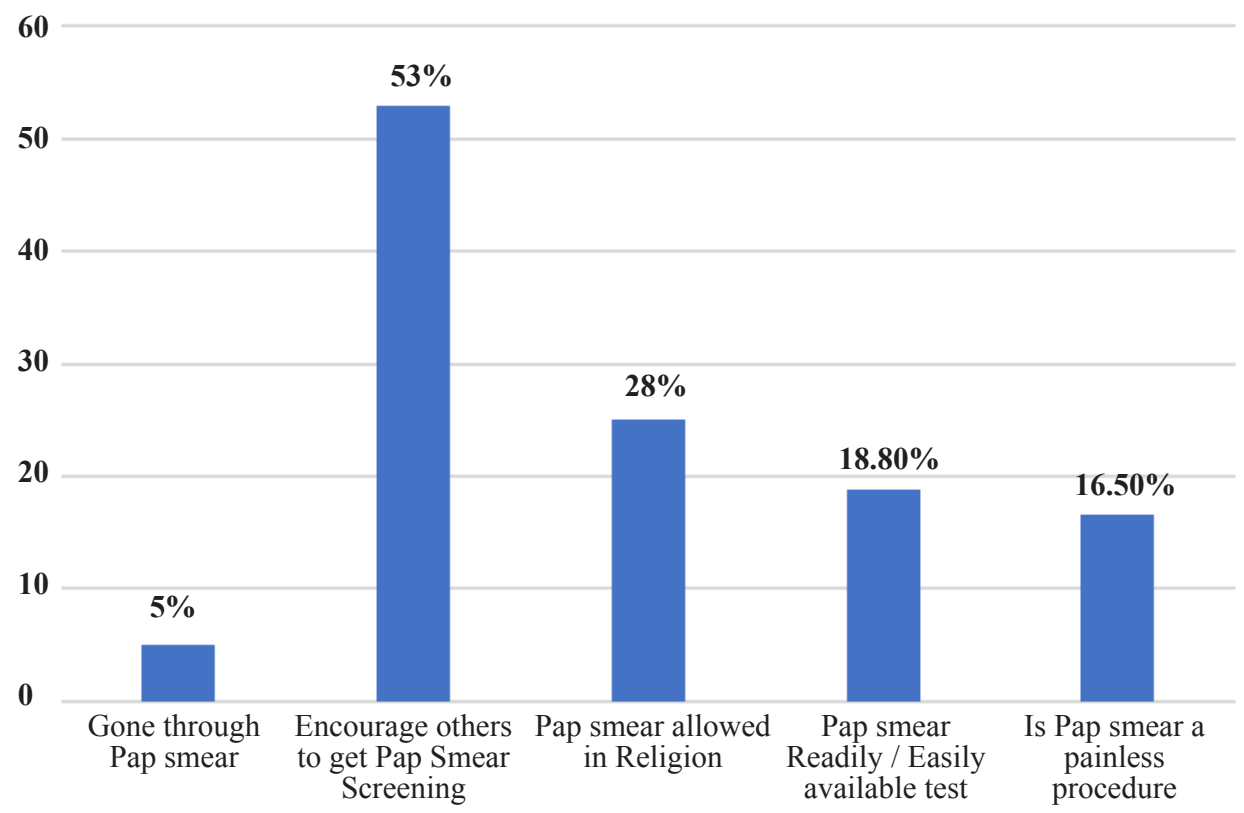

is far less than in developed countries as results similar to our study were reported in studies conducted in other developing countries such as Cameroon ${ }^{11}$ and New Delhi. ${ }^{12}$ In contrast, in developed countries, similar studies reported that $98.5 \%$ in Poland ${ }^{13}$ and $95.9 \%$ in Hong Kong ${ }^{14}$ had heard about cervical cancer. This difference can be explained because of better health education and availability of awareness programs in developed countries like Poland and Hong Kong.

Present study showed that the major source of information amongst the females who have heard about cervical cancer were doctors $(24 \%, \mathrm{n}=96)$. These findings are supported by 
another study which was done among the women in Mangalore city. ${ }^{15}$ It shows an inclining rate of doctors in educating the people and in preventing the disease. Our study reveals that few of the respondents got to know about cervical cancer via news $(10.8 \%)$ and from TV $(8.8 \%)$, in contrast other studies shows that major source of information about cervical cancer is media in Kerala $(55 \%) .{ }^{16}$ This signifies the important role of print and electronic media in awareness of cervical cancer that is lagging behind in our region.

According to the participants of our study, abnormal vaginal bleeding is the main sign and symptom for cervical cancer findings were similar to another study which showed bleeding between the periods as a major sign and symptom of cervical cancer. $^{17}$

With contextual categorization of health related factors, in this study only $21.8 \%(n=87)$ of females considered HPV infection as a major risk factor followed by multiple sexual partners $(17.3 \%, \mathrm{n}=69)$ and early marriages $(16.5 \%, \mathrm{n}=66)$. Another study reported that main risk factor for cervical cancer is infection with HPV. ${ }^{18}$ This is reflecting suboptimal knowledge of cervical cancer amongst our study population.

Results in this study showed $29.8 \%(\mathrm{n}=119)$ of respondents have heard about Pap smear while only $5 \%(n=20)$ of them had gone through this screening test. Majority responded that neither they have proper information about the test nor they have heard about it, hence signifying extreme lack of awareness in our society. Findings are similar to another study conducted in Karachi, ${ }^{19}$ that showed although $75.1 \%$ of participants had heard about pap smear only $0.01 \%$ of females had undergone this test. Similarly another study conducted in Karachi ${ }^{20}$ reported that only $13.7 \%$ of women had opted for Pap smear. Similar Findings were present in a study in India ${ }^{21}$ that showed only $3 \%$ had pap smear done in their life. In contrast, a study in London shared that $80.5 \%$ of women had undergone at least 1 pap smear and $71.5 \%$ of participants had regular smears every 3-5 years. ${ }^{22}$ This reveals that the levels of knowledge and practice of pap smear in our region is less than developed countries. Most probably the cause is that our study mainly includes married females with lesser advanced knowledge. Due to lack of awareness, most of the women were unaware of the vaccination available for the prevention of cervical cancer with the value of $32 \%$ as compared to $30.1 \%$ obtained by another study. ${ }^{23}$ Moreover majority of our respondents $(64.65 \%, \mathrm{n}=261)$ didn't have knowledge regarding HPV vaccine while only $14.6 \%(n=57)$ knew about HPV vaccination. Findings are similar to the study conducted in Bahrain $^{24}$ that showed only $3.7 \%$ had ever heard of the vaccine.

This study revealed reluctance to do Pap smear was abundantly observed in women who were never informed by the physicians and secondly because of the religious or family restrictions. This is in close association with findings of a study conducted in Karachi ${ }^{18}$ reporting that a common cause of decrease practices of pap smear is lack of urging by health care providers. Several other barriers were identified by the study conducted from a public hospital, amongst them lack of knowledge was the commonest followed by the privacy because of the male doctors during procedure. ${ }^{25}$

Majority of the women (53.8\%) agreed for going through the Pap smear screening test if they are given proper information and if it's done for free. Studies in other developing countries such as India, Nigeria and Nepal also reported positive attitude towards cervical screening despite of low knowledge. ${ }^{26}$

An interesting finding of our study was that amongst the females who had heard about cervical cancer majority were unmarried $(67 \%, \mathrm{n}=128)$ and they had more knowledge of cervical cancer and its screening. This may be because of the reason that majority of unmarried females were young population in our study, either employed or students and they may have greater opportunity for social interaction hence, they got to know more about the disease. Results of this study could not be generalized to entire population of Karachi because of the small sample size. Study conducted on a large scale with bigger sample size and more participants from different areas of Karachi can provide better results.

\section{CONCLUSION:}

The study revealed that knowledge regarding cervical cancer and Pap smear test was low among married and unmarried females. Attitudes and practices were not promising as the cost of test procedure seen as the main constraint.

\section{REFERENCES:}

1. Sankaranarayanan R. Overview of cervical cancer in the developing world: FIGO 6th Annual Report on the Results of Treatment in Gynaecological Cancer. Int J GynaecolObstet 2006; 95: Suppl 1S205-

2. Montag A, Kumar V. The Female genital system and breast; Robbin's basic pathology; Kumar V, Abbas AK, Fausto N, Mitchell RN; 8th edition; 716-21; India elsevier; 2007.

3. Aweke YH, Ayanto SY, ErsadoTl. Knowledge, attitude and practice for cervical cancer prevention and control among women of child bearing age in Hossanatown, Hadiyazone, southern Ethiopia: Community-based cross-sectional study. PLoS ONE 2017; 12(7): e0181415.

4. Touch S, et al. Knowledge, attitude and practices towards cervical cancer prevention among women in Kampong Speu Province, Cambodia. BMC cancer 2018; 15: 18(1): 294.

5. Daniyal M, Akhtar N, Ahmad S, Fatima U, Akram M, Asif HM. Update knowledge on cervical cancer incidence and prevalence in Asia. Asian Pac J Cancer Prev 2015; 16: 361720

6. Denny L. Cervical cancer: prevention and treatment. PubMed 2012; 14(75): 125-31

7. Yannikkerem E, Goker A, Piro N, et al. 2013; 28:375. A Study on knowledge and screening for Cervical cancer among women in Mangalore city. PMC 2014; 4(5): 751-756. 
8. Kamal R. Pap smear: The Life-Saving Test. The Express Turbine. 2014.

9. Imam SZ, Rehman F, Zeeshan MM, Maqsood B, Asrar S, et al. Perceptions and practices of a Pakistani population regarding cervical cancer screening. Asian Pac J Cancer Prev 2008; 9: $42-44$.

10. Batool SA, Sajjad S, Malik H. Cervical cancer in pakistan: a review. JPMA 2017; 67(7): 1074-77.

11. Tebeu PM, Major AL, Rapiti E, Petignat P, Bouchardy C, Sando Z, et al. The attitude and knowledge of cervical cancer by Cameroonian women: a clinical survey conducted in Maroua, the capital of Far North Province of Cameroon. Int J Gynecol Cancer 2008; 18: 761-5.

12. Ahlawat P, Batra N, Sharma P, Kumar S, Kumar A. Knowledge and Attitude of Adolescent Girls and Their Mothers Regarding Cervical Cancer: A Community-Based Cross-Sectional Study. J Midlife Health 2018; 9(3): 145-49.

13. Kamzol W, Jaglarz K, Tomas zewski K, Puskulluoglu M, Krzemieniecki K. Assessment of knowledge about Cervical cancer and its prevention among female students aged 17-26 years. PubMed 2013; 166(2): 196-203.

14. Lee A, Ho M, Cheung CK, Keung VM. Factors influencing adolescent girls' decision in initiation for human papillomavirus vaccination: A cross-sectional study in Hong Kong. BMC Public Health 2014; 14: 925.

15. Maree JE, Moitse KA. Exploration of knowledge of Cervical cancer and Cervical cancer screening amongst HIV positive women. PubMed 2014; 10: 37(1): 1209.

16. Aswathy S, Quereshi MA, Kurian B, Leelamoni K. Cervical cancer screening: Current knowledge \& practice among women in a rural population of Kerala, India. Indian J Med Res 2012; 136: 205-10.

17. Narayana G, Suchitra MJ, Sunanda G, Ramaiah JD, Kumar BP, Veerabhadrappa KV. Knowledge, attitude and practices towards Cervical cancer among women attending obstetrics and gynaecology department: A cross-sectional hospital based survey in South India. Indian J CANCER 2018; 54: 481-7.
18. Khan M, Zafar A, Muneer R, Siddiqui AA. Awareness Regarding Pap Smear Among Female University Students of Karachi: A Cross-sectional Survey. Cureus 2018; 10(6): e2784.

19. Ismail H, Dur -e-shahwar, Rashid MN. The knowledge, attitudes and practices (KAP) regarding human papilloma virus (HPV) among women in Karachi, Pakistan. Am J Biomed Life Sci 2017; 5: 69-72.

20. Zutshi V, Dankher S, Malik A. Cervical cancer screening and prevention: an analysis of beliefs and predictors of knowledge, attitude and practice in Northern India. Indian $\mathrm{J}$ GynecolOncolog 2017; 15 .

21. Yu CK, Rymer J. Women's attitudes to and awareness of smear testing and cervical cancer. Br J FamPlann 1998; 23: 127-33.

22. Maree JE, Moitse KA. Exploration of knowledge of Cervical cancer and Cervical cancer screening amongst HIV positive women. PubMed 2014; 10: 37(1): 1209.

23. Jassim G, Obeid A, Alnasheet HA. Knowledge, attitudes, and practices regarding cervical cancer and screening among women visiting primary health care Centres in Bahrain. BMC Public Health 2018; 18: 128.

24. Bansal AB, Pakhare AP, Kapoor N, Mehrotra R, Kokane AM. Knowledge, attitude, and practices related to cervical cancer among adult women: a hospital-based cross-sectional study. J Nat SciBiol Med 2015; 6(2): 324-328.

25. Nwankwo KC, Aniebue UU, Aguwa EN, Anarado AN, Agunwah E. Knowledge attitudes and practices of cervical cancer screening among urban and rural Nigerian women: a call for education and mass screening. Eur J Cancer Care (Engl) 2011; 20(3): 362-367.

26. Shrestha J, Saha R, Tripathi N: Knowledge, Attitude and Practice regarding Cervical Cancer Screening Amongst Women visiting Tertiary Centre in Kathmandu, Nepal 2013, 2(2): 